\title{
Management of impotence due to spinal cord injury using low dose papaverine
}

\author{
GM Yarkony ${ }^{1}$, D Chen ${ }^{2}$, J Palmer ${ }^{3}$, EJ Roth ${ }^{2}$, S Rayner ${ }^{4}$ and L Lovell \\ ${ }^{1}$ Schwab Rehabilitation Hospital, 1401 South California Boulevard, Chicago, IL 60608; ${ }^{2}$ Department of Physical \\ Medicine and Rehabilitation, Northwestern University Medical School; ${ }^{3}$ Ohio State University; ${ }^{4}$ Veterans' \\ Administration Medical Center, Sepulveda, California, USA
}

\begin{abstract}
Erectile dysfunction is a common complication of spinal cord injury. Of the 68 spinal cord injured men in whom treatment with papaverine was initiated a therapeutic dosage was determined in $50(74 \%)$. Papaverine was injected into the base of one corpora cavernosum. The dose started at $3 \mathrm{mg}$ and was increased at weekly or longer intervals until an effective dose was determined. There were $15(30 \%)$ men with tetraplegia and $35(70 \%)$ men with paraplegia. The dosage of papaverine did not relate to the level or extent of injury. Doses of $12 \mathrm{mg}$ or less were used in $56 \%$ of patients. Low dose papaverine is a safe and effective means of restoring erections in spinal cord injured men.
\end{abstract}

Keywords: sexuality; spinal cord injury; impotence; papaverine; erectile dysfunction

\section{Introduction}

Erectile dysfunction is a common complication of spinal cord injury. Several methods exist to manage this problem in spinal cord injured men seeking treatment. ${ }^{1-3}$ In our center intracavernous injection of vasoactive substances, vacuum tumescene constriction therapy and penile prostheses are available treatment options. All available methods are described to the patient and demonstrated via video tape. After discussing the risks and benefits of each technique the patient can choose the technique he prefers if there are no medical contraindications. Informed consent is required prior to intracavernous injections. This paper reports on our experience using papaverine to restore erections in spinal cord injured males.

\section{Methods}

After being made aware of the options available and the possible risks 68 spinal cord injured men chose intracorporeal injections of a vasoactive substance to treat their erectile dysfunction. Erectile dysfunction refers to the inability to get an erection, or a reflex erection which is not satisfactory for intercourse. Initial doses of $3 \mathrm{mg}$ of papaverine were injected into the base of one corpora cavernosum. If there was no response or an unsatisfactory response the patient returned to the clinic for follow-up attempts of a higher dosage at weekly or longer intervals. The dose was increased by $3 \mathrm{mg}$ papaverine per visit until a satisfactory erection was obtained. This schedule was accelerated on an individual basis due to lack of clinical response in several persons. If an erection resulted it was observed until detumescence occurred in the clinic. After a satisfactory dosage was obtained the patient or family member was instructed in self administration of the drug. Lesion level was classified according to the Standards of the American Spinal Injury Association. There were 15 tetraplegics and 35 paraplegics. Twenty eight $(56 \%)$ had complete lesions and $44 \%$ had incomplete lesions. Of those with incomplete lesions 10 $(20 \%)$ were Frankel B, seven (14\%) Frankel C, five $(10 \%)$ Frankel D and one $(2 \%)$ Frankel E.

\section{Results}

Of the 68 men who entered the program 50 completed it. Of the 50 for whom a dose was determined 44 completed the program by increasing the dose in $3 \mathrm{mg}$ increments. The doses of papaverine according to level of injury are described in Figure 1. Fifty six percent of patients required $12 \mathrm{mg}$ or less of papaverine. Doses ranged from $3 \mathrm{mg}$ to $90 \mathrm{mg}$. There was no statistical correlation between the dose and level of injury and the extent of the spinal cord injury.

Due to a lack of response at lower doses six men had their increases in dose accelerated in increments larger than $3 \mathrm{mg}$ per trial. A T6 paraplegic patient had the dose increased to $30 \mathrm{mg}$ in three doses, a C6 tetraplegic responded at $90 \mathrm{mg}$ in nine doses, and a $\mathrm{C} 7$ tetraplegic responded to $30 \mathrm{mg}$ after five sessions. Three persons were initiated at higher than the currently used doses before the current program was devised. An L1 paraplegic patient responded after treatment with a dose of 30 and $45 \mathrm{mg}$. A C8 tetraplegic patient responded to one dose of $30 \mathrm{mg}$. A T6 paraplegic patient responded after doses of 30 and $60 \mathrm{mg}$.

There were three episodes of priapism. A T8 paraplegic patient received $15 \mathrm{mg}$ papaverine at a different clinic resulting in priapism. He responded to $3 \mathrm{mg}$ papaverine with a satisfactory erection. A T12 


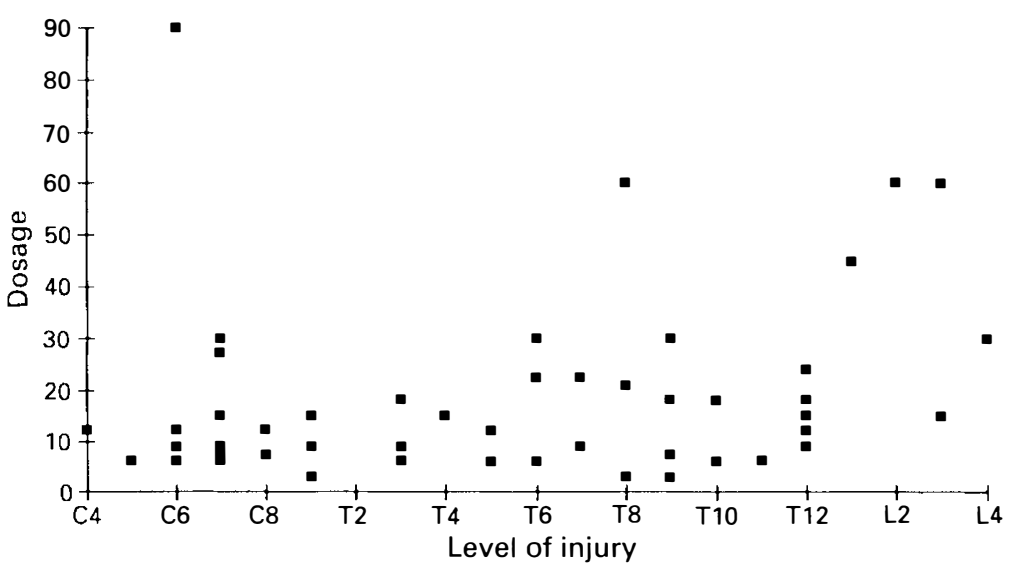

Figure 1 Dose of papaverine by level of spinal cord injury

paraplegic patient had a satisfactory erection at $9 \mathrm{mg}$ and requested a trial at $12 \mathrm{mg}$ to obtain an erection of longer duration. The $12 \mathrm{mg}$ dosage resulted in priapism. A T9 paraplegic patient had a full erection at $6 \mathrm{mg}$ without complication. During training for self injection he developed priapism with the same dose. He responded satisfactorily to $3 \mathrm{mg}$ after the episode of priapism.

Eleven men did not complete the protocol after one or more injections. Three switched to vacuum tumescence constriction therapy and three required papaverine and phentolamine in combination.

\section{Discussion}

Use of papaverine alone offers several advantages in spinal cord injury patients. It is readily available and is inexpensive. As many spinal cord injured patients are indigent, this is particularly important. Use of one drug may decrease the risk of complications such as priapism, by avoiding the use of two drugs that act at multiple sites. ${ }^{4}$ Mixing drugs increases the risk of contamination. Many of the spinal cord injured males had reflex erections that could not be achieved reliably for intercourse. Small doses of papaverine increase the reliability of this response and allows a combination of reflex stimulation along with the papaverine injection to obtain erections satisfactory for intercourse. It is not necessary to initiate treatment with higher dosages of papaverine or begin with drug combinations as previous studies recommend. ${ }^{5-7}$ Although this technique requires several clinic visits it results in the use of the lowest, safest dose. The repeat sessions can be used to initiate teaching for self injection. This technique may not be necessary for all men with spinal cord injury. Many spinal cord injured men are able to successfully engage in sexual intercourse with reflex erections and do not require any treatment. ${ }^{8}$ Papaverine usage is not without risk and has been associated with penile fibrosis. $^{9}$

There are numerous reports in the medical literature of treatment of impotence with intracavernous injections of vasoactive drugs. Papaverine injection was initially described by Virag. ${ }^{10}$ Papaverine has been used subsequently alone and in combination with phentolamine and/or prostaglandin $\mathrm{E}_{1}^{5-7,11,12}$ in patients with neuropathic impotence.

Several authors have described the use of papaverine and phentolamine mixtures and have not attempted single drug usage. ${ }^{5,6}$ Patients with neuropathic impotence required lower doses than in the vascular or other groups. ${ }^{5-7}$ Prostaglandin $\mathrm{E}_{1}$ has been compared by Earle et al $^{11}$ with papaverine in a fixed non-individualized dose and felt to be more effective and subjectively better preferred. Combinations of papaverine and prostaglandin $E_{1}$ have been demonstrated to be more effective than papayerine plus phentolamine and prostaglandin $E_{1}$ alone. ${ }^{12}$ There was a small group of neuropathic patients in this study.

Lue $^{2}$ and Lloyd ${ }^{7}$ have recommended initiating therapy in neuropathic impotence with a low dose of papaverine. Lue recommended starting with $3 \mathrm{mg}$ and Lloyd $10 \mathrm{mg}$. Our data are consistent with Lue's recommendation. Papaverine, a smooth muscle relaxant that increases arterial inflow and venous outflow resistance, ${ }^{13}$ appears to be sufficient for most spinal cord injured individuals.

We conclude that papaverine in low doses is often beneficial for the management of impotance in spinal cord injured males. It is effective at all levels and may supplement reflex erections that are not reliable at all times for intercourse. Our findings suggest that the use of the various drugs available for intracavernous injections should be individualized based on the etiology of the person's impotence.

\section{Acknowledgements}

This study was supported in part by grants H133B80007 and H133N0008 from The National Institute of Disability and Rehabilitation Research, US Department of Education.

\section{References}

1 Brindley GS. Pilot experiments on the action of drugs injected into the human corpas cavernosum penis. Br J Pharmacol 1986; 87:495-500. 
2 Lue TF, Tanagho EA. Physiology of erection and pharmacological management of impotence. J Urol 1987; 137: 829-836.

3 Virag $\mathrm{R}$ et al. Intracavernous self-injection of vasoactive drugs in the treatment of impotence: 8 year experience with 615 cases. J Urol 1991; 145: 287-293.

4 Lee M, Sharifi R. Information and treatment with intracavernous injections of papaverine and phentolamine. Letter to the Editor. J Urol 1987; 137: 1008-1010.

5 Wyndaele JJ, deMeyer JM, deSy WA, Claesseus H. Intracavernous injection of vasoactive drugs, an alternative for treating impotence in spinal cord injury. Paraplegia 1986; 24: 271-275.

6 Sidi AA, Cameron JS, Duffy LM, Lanje PH. Intracavernous drug-induced erections in the management of male erectile dysfunction: experience with 100 patients. J Urol 1986; 135: 704-706.

7 Lloyd L, Richards JS. Intracavernous pharmacotherapy for management of erectile dysfunction in spinal cord injury. Para- plegia 1989; 27: 457-464.

8 Siosteen A et al. Sexual ability, activity, attitudes and satisfaction as part of adjustment in spinal cord injured subjects. Paraplegia 1990; 28: 285-295.

$9 \mathrm{Hu} \mathrm{KN}$, Burks C, Christy WC. Fibrosis of tunica albuginea: complication of long-term intracavernous pharmacological selfinjection. J Urol 1987; 138: 404-405.

10 Virag R. Intracavernous injection of papaverine for erectile failure. Letter to the Editor. Lancet 1982; 2: 938.

11 Earle $\mathrm{CM}$ et al. Prostaglandin $\mathrm{E}_{1}$ therapy for impotence, comparison with papaverine. J Urol 1990: 143: 57-59.

12 Floth A, Schramek P. Intracavernous injection of prostaglandin E1 in combination with papaverine: enhanced effectiveness in comparison with papaverine plus phentolamine and prostaglandin E1 alone. J Urol 1991; 145: 56-59.

13 Juenemann KP, Lue TF, Fournier Jr GR, Tanagho EA. Hemodynamics of papaverine and phentolamine-induced penile erection. J Urol 1986; 136: 158-161. 